\title{
Life style as a risk factor of human Papillomavirus co-infections with Trichomonas vaginalis in female sex workers
}

\author{
Efosa Bolaji Odigie* and Micheal Awol Okungbowa*
}

\section{ABSTRACT}

\section{BACKGROUND}

Asymptomatic Trichomonas vaginalis (TV) and human papillomavirus (HPV) co-infection is perceived to have a devastating combined effect on victims. Hence, we investigated TV/ HPV co-infection and determined the risk factors associated with it in female sex workers (FSW).

\section{METHODS}

A cross-sectional study was used to recruit 338 subjects from 6 local government areas (LGAs) in Nigeria for 18 months. Agglutination tests for blood samples, and direct and wet examination of urine and vaginal swabs were conducted in the laboratory. Life style of FSWs was surveyed; data were analyzed with Chi-Square test $\left(\mathrm{X}^{2}\right)$, paired and unpaired t-test and logistic regression analysis with statistical significance set at $\mathrm{p}<0.05$.

\section{RESULTS}

Life style characteristics were significantly associated with HPV and TV co-infection $(\mathrm{p}<0.001)$. The model explained 49.9\% (Nagelkerke R2) of the variance in infections among FSWs and effectively classified $93.2 \%$ of cases. Those involved in oral sex were 1.795 times more likely to be infected compared to those not involved (OR: 1.795; 95\% C.I.: 1.005 - 33.525; $p=0.001)$. Street and residential FSWs all have increased likelihood of being infected. Hard drug usage was also associated with an increased likelihood of being infected with the disease (OR: 3.582; 95\% C.I.: 1.573 - 11.756; $\mathrm{p}=0.001)$.

\section{CONCLUSIONS}

Life style (hard drug usage and oral sex practices) was observed in association with HPV/ TV co-infection in FSWs with a preponderance of $49.9 \%$. This study demonstrated the value of screening for genital infections in HPV positive subjects in order to reduce the probable synergistic effects of co-infections.

Keywords: Co-infection, female sex workers, human papillomavirus, Trichomonas vaginalis
*Department of Medical Laboratory Science, School of Basic Medical Sciences, College of Medical Sciences, University of Benin, Nigeria

Correspondence: ODIGIE Bolaji Efosa (PhD) Department of Medical Laboratory Science (Histopathology Unit), School of Basic Medical Sciences, College of Medical Sciences, University of Benin, Benin City, Edo State, Nigeria.

Email: bolaji.odigie@uniben.edu GSM: +2348023345132 ORCID ID: http://orcid.org/00000002-1233-0491

Date of first submission, August 14, 2018

Date of final revised submission, March 19, 2019

Date of acceptance, March 20, 2019

This open access article is distributed under a Creative Commons AttributionNon Commercial-Share Alike 4.0 International License

Cite this article as: Odgie, Okungbowa. Life style as a risk factor of human Papillomavirus co-infections with Trichomonas vaginalis in female sex workers. Univ Med 2019;38:17-24. doi: 10.18051/UnivMed.2019.v38. $17-24$ 


\section{INTRODUCTION}

Sexual contact is the main form of transmission of human papillomavirus (HPV), which causes one of the most common cervical infections in the world. As such, female sex workers (FSW) who engage in unwholesome activities are cut up with different kinds of infection. ${ }^{(1)}$ Female sex workers constitute a vulnerable group for the development of cervical cancer precursor lesions, since they are constantly exposed to risk factors that facilitate the spread. It has been revealed that sex work is a predisposing factor for acquiring sexually transmitted diseases (STDs). ${ }^{(2)}$ However, STDs are commonly available in the general population irrespective of age, sex, tribe, socioeconomic class, and types of exposure. ${ }^{(1,3)}$ Epidemiology of viral co-infection with other forms of infective organisms in Nigeria has been studied among sex workers. ${ }^{(4)}$ It is likely that the prevalence of viral co-infection in Nigeria may be the same irrespective of the occupation in different sectors of the Nigerian population. ${ }^{(2)}$ A report has it that the rate of co-infection amongst the different infective organisms in Nigeria may be higher compared to other countries in the West-African sub-region due to her population. ${ }^{(4)}$ Co-infection may differ according to populations at risk (e.g. FSW); geographical locations, and individual lifestyle, which are important factors for consideration. ${ }^{(5)}$

Transactional sex is a critical factor for acquiring Trichomonas vaginalis (TV) and human papillomavirus (HPV) infections. Combined health effects from TV and HPV coinfection in a host could be devastating and may result in a more harmful health implication. Trichomonas vaginalis, a common motile protozoan parasite, is the most prevalent non-viral sexually transmitted infection (STI) in the world, having a complex social and public health implications, in addition to their medical significance. ${ }^{(6)}$ In combination with an HPV infection, the combined effects may become more harmful and devastating on the sufferers. Human papillomavirus in turn is a type of viral infection that has been associated with cervical cancer and with substantial evidence for cancers in other anogenital regions, like the anus, vulva, penis and vagina in recent times. ${ }^{(7)}$ Very similar to the disposition of TV in women, HPV is also the most common sexually transmitted infection of viral origin and with over $100 \mathrm{HPV}$ types, which have been reportedly identified and of which over 40 of the species can infect the genital areas. ${ }^{(7,8)}$

Investigations revealed that females with TV infection are more predisposed to HPV coinfection. Combined HPV and TV infection has been reported in Tanzania ${ }^{(9)}$, which resulted in TV having a strong association with HPV $[\mathrm{OR}=4.2 ; 95 \%$ CI. 1.7-10.3)]. Subjects infested with TV were reported to be 6.5 times potentially exposed to HPV type 16 than those negative for TV $(50 \%$ vs. $13.3 \%)[\mathrm{OR}=6.5 ; 95 \%$ C.I. 1.1 3.7)]. A study conducted in Belgium involving 62,944 liquid-based Papanicolaou smears with polymerase chain reaction for detecting both infections, observed that about $15.1 \%$ of women had an HPV infection and $0.37 \%$ had co-infection with TV. ${ }^{(10)}$ Also, working in the sex industry had an increased risk of HPV co-infection with TV compared to other women in the general population $(\mathrm{OR}=8.6 ; 95 \%$ C.I. $4.4-16.9) .{ }^{(10)} \mathrm{Life}$ styles, which has been termed behaviorally risk factors in this study, include characteristics of a woman's sexual history (number of partners, characteristics of the partners, contraceptive use) and substance use history (alcohol, cigarettes, illicit drugs), including oral and anal sex practices, have been well discussed in some studies. ${ }^{(9,10)}$ Of the sexual history characteristics, increased number of lifetime sexual partners and having had a recent, new sexual partner are two factors that are unswervingly associated with an increased risk of HPV infection. ${ }^{(10)}$

Sex workers are most disadvantaged by their occupation in a TV/HPV asymptomatic coinfection due to poor access to proper healthcare. (1) Association between different STIs is frequent, but there are few studies on the prevalence of HPV co-infection with TV in the 
high risk group of FSWs. We assume that these women have a higher number of risk factors for acquiring the infection, which ranges from hard drugs, irregular condom usage and oral sex practices of the affected women. This study aimed at investigating the risk factors associated with HPV and TV co-infections in FSWs.

\section{METHODS}

\section{Study area}

The study focused on the Afemai communities in Etsako local government areas (LGAs) within the northern part of Edo State, which is located in the south-southern region of Nigeria. It is located about 103 miles north-east of Benin City and geographically located on latitudes $6^{\circ} 10^{1} \mathrm{~N}$ and $6^{\circ} 20^{1} \mathrm{~N}$ and longitudes $6^{\circ}$ $10^{1} \mathrm{E}$ and $6^{\circ} 15^{1} \mathrm{E}$ (Figure 1). Cloth weaving, farming, and fishing are essential occupations of the Afemai Clan who are known as the Ivbiosakon.

\section{Research design}

We used a cross-sectional study design to explore TV/HPV co-existence including relationship between TV and HPV in FSWs through neighbourhood outreach. The study was conducted between June 2016 and December 2017.

\section{Study subjects and sample size determination}

Participants were a combination of street and resident female sex workers who are engaged in the commercial sex business for a minimum of 1 year. Pregnant women and women with bloody discharge were excluded. We investigated apartments, red light junctions, and guest houses where the exchange of sex for money is transacted. We adopted the sample size determination according to the study by Odigie and Achukwu ${ }^{(13)}$ in which the authors used the Fisher's formula $\left(\mathrm{n}=\mathrm{Z}_{\alpha}^{2} \cdot \mathrm{p} \cdot \mathrm{q} / \mathrm{d}^{2}\right)$ to determine their sample size. The desired sample size is $n$, the standard deviation (1.96) is $Z_{\alpha}$, and $p$ is the marked proportion of the population, which was estimated to have a particular characteristic (i.e., coinfection of TV/HPV). However, since no reasonable estimate exists, we assume $50 \%$ (i.e., $0.5)$ for $\mathrm{P}$ with regards to another study in a different location. ${ }^{(14)}$ A total of 352 subjects who understood the research aims were included into the study.

\section{Data collection}

A reliable and validated questionnaire was distributed amongst the subjects prior to sample collection. It was completed voluntarily and conducted in the vernacular in some instances. ${ }^{(13)}$ One on one consultation was also used sometimes, while the question types were more of multiple-choice and open-ended options. Data gathering information focused on the sociobehavioral background, which includes working duration per day, commercial sex frequency, and irregular use of condoms. Health-care related issues, sexual exploitation, and history of previous or present infections (TV and/or HPV), including current and former symptoms (if known) were also part of the questionnaire. ${ }^{(1)}$

\section{Laboratory analysis}

About 3-4 $\mathrm{ml}$ of venous blood was aseptically collected using a $5 \mathrm{~mL}$ syringe and emptied into a sterile container without anticoagulant with tab gel and centrifuged (BROADBENT, UK) at $3000 \mathrm{rpm}$ for $5 \mathrm{~min}$ to obtain the serum content. Thereafter, serum separated from whole blood was used for serology/agglutination tests using HPV ${ }^{(12)}$ and $\mathrm{TV}^{(15)}$ kits in line with the manufacturer's instructions. High vaginal swabs (HVS) and midstream urine (MSU) specimens were collected for microscopy (direct and wet preparation). Other screening methods were used, which include: point-of-care Trichomonas assay, ${ }^{(6)}$ rapid antigen testing for trichomoniasis, ${ }^{(6,11)}$ rapid diagnostic method, ${ }^{(15)}$ and OSOM Trichomonas rapid test. ${ }^{(16)}$ In addition, uncertain HPV results were confirmed with enzyme-linked immunosorbent assay (high-risk human papillomavirus testing kits). ${ }^{(17)}$ 


\section{Data analysis}

We analyzed the empirical data with ChiSquare test $\left(\mathrm{X}^{2}\right)$, paired and unpaired t-test and logistic regression analysis using Minitab version 17.0. $\mathrm{X}^{2}$ tests. Statistical tests were considered significant if $\mathrm{p}<0.05$.

\section{Ethical clearance}

Information on the approved ethics clearance from the Edo State Ministry of Health is available in protocol numbers (HA. 577/Vol. 11. 165). The subjects were adequately briefed on the research protocols, while the informed consents were obtained before sample collections with adequate explanations of the risk involved in the procedures.

\section{RESULTS}

Out of 352 initial subjects, data from only 338 subjects were accepted for analyses due to inadequacy or quality of the specimen in addition to some missing or incomplete data observed for TV (08) and HPV (06). Missing values were randomly distributed among the FSWs (asymptomatic, residential, street etc.), which are unlikely to have introduced bias. Therefore, there exists a preponderance of 1:10.2 representing 33/ 338 of FSWs who play host to HPV co-infections with TV in the study areas (Table 2). Life style of FSWs (hard drug usea and oralsex practices) was highly implicated and significantly expressed in HPV/TV co-infections (Table 2). The result of the multiple logistic regression model, which was conducted to ascertain life styles characteristics associated with HPV and TV coinfection among female sex workers (FSWs) in the affected LGAs of Edo State, Nigeria was statistically significant, $\chi 2(7)=90.97, \mathrm{p}<0.001$. The model explained $49.9 \%$ (Nagelkerke $\mathrm{R}^{2}$ ) of the variance in infections among sex workers and correctly classified $93.2 \%$ of cases. Those involved in oral sex were 1.795 times more likely to be infected compared to those not involved (OR:1.795; CI: $1.005-33.525 ; p=0.001)$. Street FSW and residential FSWs all have increased likelihood of being infected. And hard drug use was associated with an increased likelihood of being infected with the disease (OR: 3.582; CI: 1.573 - 11.756; $\mathrm{p}=0.001)$.

Table 1. Distribution of socio-behavioral characteristics of FSW in TV infection and HPV infection $(n=338)$

\begin{tabular}{|c|c|c|c|c|c|c|}
\hline \multirow[b]{2}{*}{ Parameters } & \multicolumn{3}{|c|}{ TV infection } & \multicolumn{3}{|c|}{ HPV infection } \\
\hline & TV $^{(-)}(n=262)$ & $\begin{array}{c}\mathrm{TV}^{(+)} \\
(\mathrm{n}=76)\end{array}$ & $\begin{array}{c}\text { p- } \\
\text { value }\end{array}$ & $\begin{array}{l}\mathrm{HPV}^{(-)} \\
(\mathrm{n}=\mathbf{2 7 9})\end{array}$ & $\begin{array}{c}\mathbf{H P V}^{(+)} \\
(\mathbf{n}=\mathbf{5 9})\end{array}$ & $\begin{array}{c}\text { p- } \\
\text { value }\end{array}$ \\
\hline Mean age (yrs) & $26.8 \pm 3.05$ & $28.4 \pm 3.11$ & & $28.6 \pm 2.18$ & $28.2 \pm 3.09$ & \\
\hline $\begin{array}{l}\text { Mean work } \\
\text { duration }\end{array}$ & $2.84 \pm 0.42$ & $2.88 \pm 0.16$ & & $2.84 \pm 0.12$ & $3.16 \pm 0.25$ & \\
\hline $\begin{array}{l}\text { Sex work (12hrs) } \\
\text { per day }\end{array}$ & $14.75 \pm 1.12$ & $\begin{array}{c}16.22 \pm \\
1.28\end{array}$ & & $14.16 \pm 1.63$ & $\begin{array}{c}15.22 \pm \\
1.82\end{array}$ & \\
\hline $\begin{array}{l}\text { Irregular condom } \\
\text { use }\end{array}$ & $\begin{array}{l}253 / 262 \\
(96.6 \%)\end{array}$ & $\begin{array}{c}21 / 76 \\
(27.6 \%)\end{array}$ & 0.021 & $\begin{array}{l}253 / 279 \\
(90.7 \%)\end{array}$ & $\begin{array}{c}18 / 59 \\
(30.5 \%)\end{array}$ & 0.011 \\
\hline Hard drug use & $\begin{array}{l}81 / 262 \\
(30.9 \%)\end{array}$ & $\begin{array}{c}53 / 76 \\
(69.7 \%)\end{array}$ & 0.644 & $\begin{array}{l}88 / 279 \\
(31.5 \%)\end{array}$ & $\begin{array}{l}45 / 599 \\
(76.3 \%)\end{array}$ & 0.644 \\
\hline Anal sex practice & $\begin{array}{c}91 / 262 \\
(34.7 \%)\end{array}$ & $\begin{array}{c}13 / 76 \\
(17.1 \%)\end{array}$ & $\underset{*}{0.043}$ & $\begin{array}{l}101 / 279 \\
(36.2 \%)\end{array}$ & $\begin{array}{c}11 / 59 \\
(18.6 \%)\end{array}$ & $\underset{*}{0.043}$ \\
\hline Alcohol intake & $\begin{array}{l}128 / 262 \\
(48.9 \%)\end{array}$ & $\begin{array}{c}43 / 76 \\
(56.6 \%)\end{array}$ & 0.004 & $\begin{array}{l}136 / 279 \\
(48.7 \%)\end{array}$ & $\begin{array}{c}21 / 59 \\
(35.6 \%)\end{array}$ & $\underset{*}{0.002}$ \\
\hline Oral sex practice & $\begin{array}{c}71 / 262 \\
(27.1 \%)\end{array}$ & $\begin{array}{c}29 / 76 \\
(38.2 \%)\end{array}$ & 0.112 & $\begin{array}{c}93 / 279 \\
(33.3 \%)\end{array}$ & $\begin{array}{c}28 / 59 \\
(47.5 \%)\end{array}$ & 0.112 \\
\hline Street FSW & $\begin{array}{l}172 / 262 \\
(65.6 \%)\end{array}$ & $\begin{array}{c}18 / 76 \\
(23.7 \%)\end{array}$ & 0.204 & $\begin{array}{l}107 / 279 \\
(38.4 \%)\end{array}$ & $\begin{array}{c}31 / 59 \\
(52.5 \%)\end{array}$ & 0.204 \\
\hline Residential FSW & $\begin{array}{c}90 / 262 \\
(34.4 \%)\end{array}$ & $\begin{array}{c}58 / 76 \\
(76.3 \%)\end{array}$ & 0.001 & $\begin{array}{l}172 / 279 \\
(61.6 \%)\end{array}$ & $\begin{array}{c}28 / 59 \\
(47.5 \%)\end{array}$ & $\underset{*}{0.001}$ \\
\hline
\end{tabular}

Note: Data presented as Mean $\pm \mathrm{SD} ; \mathrm{n}(\%) ; \mathrm{X}^{2}$ test with Yate's correction was used in obtaining the p-values 
Table 2: Multiple logistic regression analysis of life styles characteristics associated with HPV and TV co-infection in FSWs

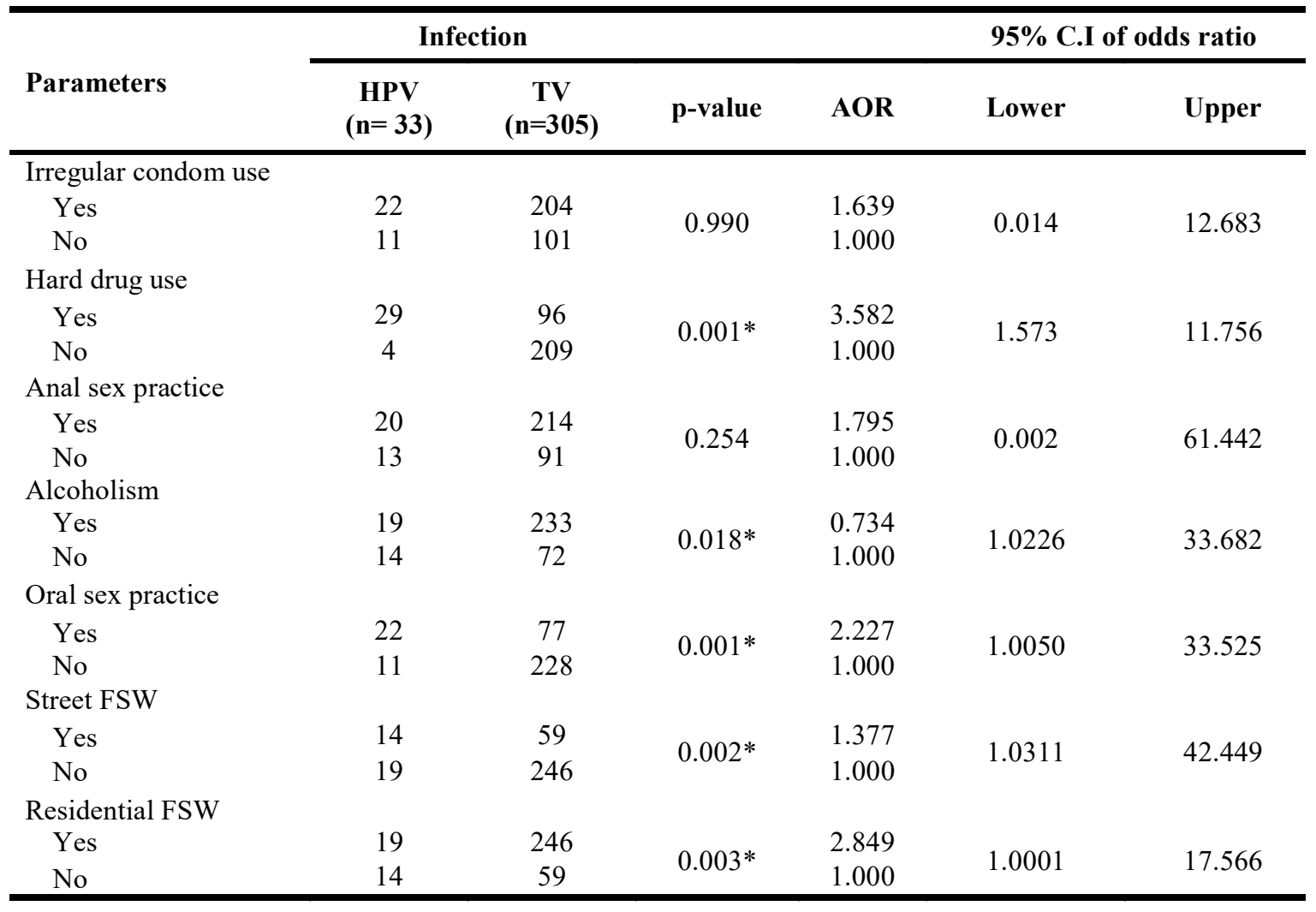

Note: $\mathrm{CI}=$ confidence interval; FSW = female sex worker; $\mathrm{HPV}=$ human papillomavirus; $\mathrm{AOR}=$ adjusted odds ratio; $\mathrm{TV}=$ Trichomonas vaginalis

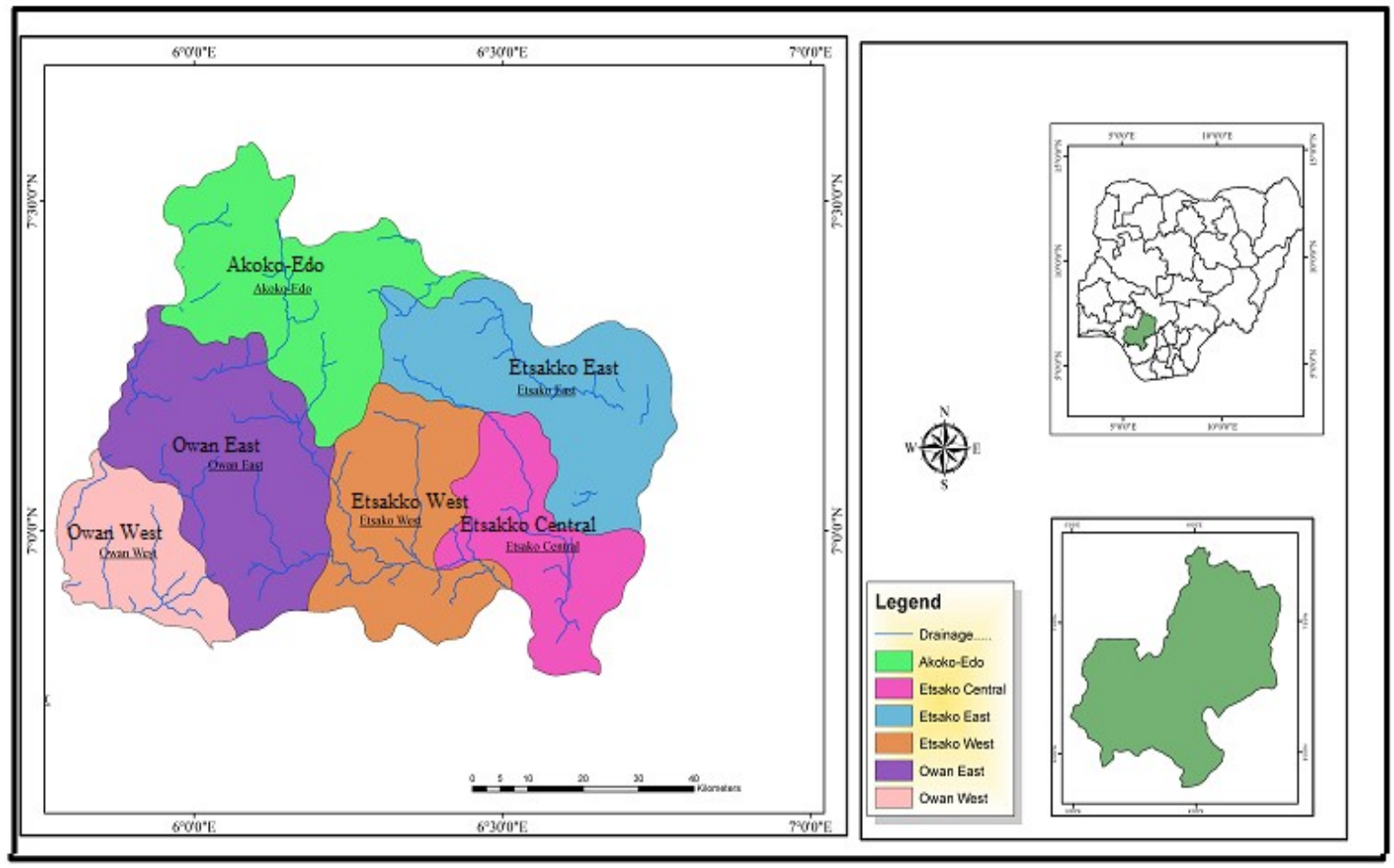

Figure 1: Map is showing focal areas within Afamai clans in Etsakko LGAs of Edo state, Nigeria 


\section{DISCUSSION}

Many factors have been linked to sales of sex including poverty, ${ }^{(13)}$ which is a characteristic of a depressed economy. ${ }^{(18,19)}$ We observed that oral sex practices have a significant bias in acquiring HPV/TV co-infections by FSWs. Oral sex particularly has been reported as a typical root of spreading genital HPV through sustained direct skin-to-skin contact with anal sex being the most common mode of transmission. ${ }^{(13)}$ Also observed are the degree of TV infection and the number of HPV/TV co-infections amongst residential FSWs, while HPV infection is commoner in street sex workers, with the majority being asymptomatic carriers of the infection.

In our study, residential FSWs are resident in a particular brothel used for commercial sex activities waiting for male client's patronage. ${ }^{(13)}$ Street FSWs in turn, are seen as female commercial sex workers who move from one location to another searching for clients. ${ }^{(1)}$ The difference here is the male "clients"; in the case of residential FSWs, male clients are in search of FSWs, but in the case of street sex workers, FSWs scout for male clients. ${ }^{(1)}$ Street sex workers ${ }^{(13)}$ and resident commercial sex workers ${ }^{(5)}$ have been reported to be active carriers of co-infections in women compared to their counterparts in the general population. This statement expresses the that all FSWs whether residential or street-based are considered as high-risk individuals. ${ }^{(2,5)}$

Our result agrees with Samarawickrema et al. ${ }^{(14)}$ in which co-infection resulting from TV, HPV, Chlamydia trachomatis, and Neisseria gonorrhoeae were significantly observed in a sexual health clinic setting in urban Sri Lanka. Co-infection with viruses, ${ }^{(13)}$ bacteria, ${ }^{(20,21)}$ helminths, ${ }^{(22)}$ yeast/fungi, ${ }^{(23)}$ and other forms of infections has been documented. ${ }^{(7,23)}$ To further corroborate our finding, Ogunkan et al. ${ }^{(19)}$ reported that HPV infection in FSWs co-exists with other infections apart from viruses, with the prevalence varying from one region to another. This is not unanticipated, as it has been argued that sex works play a crucial role in the realization of HIV/HPV co-existence with some infective organisms thereby leading to a massive immunological breakdown in host systems. ${ }^{(24)}$ The mechanism by which TV and HPV shares a common ground in a host has been explained. ${ }^{(23)}$ Cell-mediated immunity generated against an invading organism involves recruitment of leucocytes in large numbers. ${ }^{(24)}$ Trichomonas often imbibes nutritious elements like fatty acids and iron by the destruction of host red blood cells. ${ }^{(23)}$ This is caused by cytotoxic trypsin-like substances called cell detaching factor (CDF) and N-nitrosamines liberated during infection, which subsequently promote the process of epithelial atypia and dysplasia that is observable in cervical cytology. ${ }^{(24,25)}$

Our study is comparable with the reports by Taj and Jamil ${ }^{(20)}$ and Gomih-Alakija et al. ${ }^{(25)}$ in which co-infections of Mycoplasma genitalium and HPV and of HIV and TV were observed in FSWs. However, it was reported ${ }^{(24)}$ that a prolonged HPV/TV co-infection may enhance the risk of cervical intraepithelial neoplasia grade 3 (CIN 3). Human papillomavirus positive women co-infected with TV had a higher risk of cervical cancer in a study on the association between TV and high-risk HPV in rural Tanzanian women undergoing cervical cancer screening. ${ }^{(9)}$

Irregular condom usage has been revealed in notable studies, ${ }^{(26,27)}$ which is dissimilar to the finding in this study. We suggest that there is a likelihood of not using condoms regularly in certain situations like the non-availability of condoms at the time of sexual encounter, ${ }^{(26)}$ or in a situation where the last condom gets burst at the point of affixing it. The present report differed from some studies probably due to bias responses from the subjects, which may have introduced the differences observed as against other research outcomes. ${ }^{(1)}$ The major drawbacks in the present study centres on population size (number of participants), the limited time frame to consult with FSWs and meandering pattern of sex workers (residential FSWs), as well as changes in location, which is 
commoner with street FSWs in Nigeria. ${ }^{(1)}$ The implication of this study is that co-infection could be detrimental to human health if proper attention is not promptly apportioned. An understanding of the nature and consequences of an HPV/TV co-infection is vital for accurate estimates of infectious disease burden especially in FSWs living in a depressed economic society. In particular, more holistic data on infectious diseases would help to quantify the size of the effects of HPV/TV co-infection on human health. From the foregoing, it therefore appears that a long-term assessment of cohort studies may be required to adequately evaluate the influences of HPV/TV co-infection, pathogenesis, combined role and interactions of a dual infection (HPV-TV) on their host.

In the future, further studies should investigate the carcinogenic effects of coinfection on the uterine cervix in FSWs. It should endeavour to look critically into the association/ co-existence of STDs in a large-scale research using the polymerase chain reaction for assessment.

\section{CONCLUSIONS}

We therefore conclude that HPV co-exists with TV in female sex workers with a preponderance of $1: 10.2$ and was highly implicated by life-style (hard drug use and oral sex practices) of the subjects. This study demonstrated the value of screening for genital infections in HPV positive patients in order to reduce the probable synergistic effects of coinfections.

Financial Support and Sponsorship: Selfsponsored.

CONFLICTS OF INTEREST: None.

\section{ACKNOWLEDGEMENTS}

All members of Sexual Health Concerns for Commercial Sex Workers (SHCCSW)
Research Group, University of Benin are well appreciated for the providence of adequate workforce in field exercises.

\section{CONTRIBUTORS}

All authors immensely contributed to the drafting of the manuscript. OMA and OEB indorsed the conception and design of the study. All authors participated in acquisition of data and field exercises. OEB and OMA funded the data analysis and interpretation. All authors critically revised the manuscript for valuable intellectual content. OEB acted as the corresponding author on behalf of the first author. All authors have read and approved the final draft.

\section{REFERENCES}

1. Odigie EB, Achukwu PU. Regular condom use tends to decrease the cervical lesions in residentcommercial sex workers in sub-Saharan Africa. Univ Med 2018;37:39-49. DOI: http://dx.doi.org/ 10.18051/UnivMed.2018.v37.39-49.

2. Duron S, Panjo H, Bohet A, et al. Prevalence and risk factors of sexually transmitted infections among French service members. PLoS ONE 2018;13:e0195158. DOI: https://doi.org/10.1371/ journal.pone.0195158.

3. Szwarcwald CL, Damacena GN, Borges de SouzaJunior PR et al. Factors associated with HIV infection among female sex workers in Brazil. Medicine 2018;97 Suppl:S54-61. doi: 10.1097/ MD.0000000000009013.

4. Umego CF, Mboto CI, Mbim EN, et al. Epidemiology of hepatitis $\mathrm{B}$ virus infection in South-South Nigeria: a review. Int STD Res Rev 2018;7:1-17. doi: 10.9734/ISRR/2018/36989.

5. Nasirian M, Kianersi S, Hosseini SG, et al. Prevalence of sexually transmitted infections and their risk factors among female sex workers in Isfahan, Iran: a cross-sectional study. J Int Assoc Provid AIDS Care 2017;16:608-14. DOI: https:// doi.org/10.1177/2325957417732836

6. Gaydos CA, Klausner JD, Pai NP, et al. Rapid and point-of-care tests for the diagnosis of Trichomonas vaginalis in women and men. Sex Transm Infect 2017;93:S31-5. doi: 10.1136/ sextrans-2016-053063.

7. Bruni L, Barrionuevo-Rosas L, Albero G, et al. for ICO Information Centre on HPV and Cancer (HPV 
Information Centre). Human papillomavirus and related diseases in the world: summary report 27 July 2017. Barcelona, Spain: ICO/IARC HPV Information Centre;2017.

8. Noel JC, Fayt I, Romero-Munoz MR, et al. High prevalence of high-risk human papillomavirus infection among women with Trichomonas vaginalis infection on monolayer cytology. Arch Gynecol Obstet 2010;282:503-5. DOI: 10.1007/ s00404-009-1291-x.

9. Lazenby GB, Taylor PT, Badman BS, et al. An association between Trichomonas vaginalis and high-risk human papillomavirus in rural Tanzanian women undergoing cervical cancer screening. Clin Ther 2014;36:38-45. doi:10.1016/ j.clinthera.2013.11.009.

10. Depuydt CE, Leuridan E, Van Damme P, et al. Epidemiology of Trichomonas vaginalis and human papillomavirus infection detected by realtime PCR in Flanders. Gynecol Obstet Invest 2010;70:273-80. doi: 10.1159/000314017.

11. Postenrieder NR, Reed JL, Hesse E, et al. Rapid antigen testing for trichomoniasis in an emergency department. Pediatrics 2016;137:e20152072. doi 10.1542/peds.2015-2072.

12. Saslow D, Andrews KS, Manassaram-Baptiste D, et al. Human papillomavirus vaccination guideline update: American Cancer Society guideline endorsement. CA Cancer J Clin 2016; 66:375-85. doi: $10.3322 /$ caac. 21355 .

13. Menon S, Davy VB, Rodolfo R, et al. Multiple HPV infections in female sex workers in Western Kenya: implications for prophylactic vaccines within this subpopulation. Infect Agents Can 2017;12:2. doi: 10.1186/s13027-016-0114-5.

14. Samarawickrema NA, Tabrizi SN, Young E, et al. Prevalence of Trichomonas vaginalis, Chlamydia trachomatis, Neisseria gonorrhoeae and human papillomavirus in a sexual health clinic setting in urban Sri Lanka. Int J STD AIDS 2015; 26: 733-9. doi: $10.1177 / 0956462414552813$.

15. Gaydos CA, Hobbs M, Marrazzo J, et al. Rapid diagnosis of Trichomonas vaginalis by testing vaginal swabs in an isothermal helicasedependent AmpliVue assay. Sex Transm Dis 2016; 43:369-73.

16. Madhivanan P, Li T, Trammell S, et al. Performance of the OSOM Trichomonas Rapid Test for diagnosis of Trichomonas vaginalis infection among women in Mysore, India. Sex Health 2013;10:320-4. doi: 10.1071/SH13015.
17. Huh WK, Ault KA, Chelmow D, et al. Use of primary high-risk human papillomavirus testing for cervical cancer screening: interim clinical guidance. Obstet Gynecol 2015; 125:330-7. doi: 10.1097/AOG0000000000000669.

18. Ojo OD, Ugochukwu NDA. Impacts of societal prejudice on attainment of life/personal goals of physically challenged persons in Nigeria. Int Res J Human 2012;4:12-35.

19. Ogunkan DV, Omoruan A, Fawole O. Environmental and socio-economic dimensions of prostitution in Ogbomoso, Oyo State. Ife Res Publ Geogr 2010;9:282-300.

20. Taj A, Jamil N. Viral and bacterial coinfection in patients with neurological disorders: an analytical cross-sectional study from Karachi. Clin Infect Dis 2018;2:108-13.

21. El Baroudy NR, El Refay AS, Abdel Hamid TA. Respiratory viruses and atypical bacteria coinfection in children with acute respiratory infection. Open Access Maced J Med Sci 2018;6:1588-93. DOI: https://doi.org/10.3889/ oamjims.2018.332.

22. Okungbowa MA, Omorodion TN. Environmental and clinical implications of helminthic infection: a brief review. Am J Biomed Sci 2018;10:45-8. doi:10.5099/aj180100045.

23. McArdle AJ, Turkovab A, Cunningtonc AJ. When do co-infections matter? Curr Opin Infect Dis 2018;31:209-15. doi:10.1097/ QCO.0000000000000447.

24. Ghosh S, Mandal R, Kundu P, et al. Association of genital infections other than human papillomavirus with pre-Invasive and invasive cervical neoplasia. J Clin Diagn Res 2016;10:Xe01 -6. doi: 10.7860/JCDR/2016/15305.7173.

25. Gomih-Alakija A, Ting J, Mugo N, et al. Clinical characteristics associated with Mycoplasma genitalium among female sex workers in Nairobi, Kenya. J Clin Microbiol 2014;52:3660-6. doi: 10.1128/JCM.00850-14.

26. Johnston LG, Bonilla L, Caballero T, et al. Associations of HIV testing, sexual risk and access to prevention among female sex workers in the Dominican Republic. AIDS Behav 2017;21:2362-71. doi: 10.1007/s10461-017-1751-4.

27. Nadol P, Hoang TV, Le LV, et al. High HIV prevalence and risk among male clients of female sex workers in Hanoi and Ho Chi Minh City, Vietnam. AIDS Behav 2017;21:2381-393. doi: 10.1007/s10461-017-1751-4. 